\title{
Lumbar Epidural Varix Mimicking Perineural Cyst
}

\author{
Serhat Pusat ${ }^{1}$, Cahit Kural ${ }^{1}$, Atilla Aslanoglu ${ }^{2}$, Bulent Kurt ${ }^{3}$, Yusuf Izci ${ }^{1}$ \\ ${ }^{I}$ Department of Neurosurgery, Gulhane Military Medical Academy, Ankara, Turkey \\ ${ }^{2}$ Department of Radiology, Beytepe Military Hospital, Ankara, Turkey \\ ${ }^{3}$ Department of Pathology, Gulhane Military Medical Academy, Ankara, Turkey
}

Lumbar epidural varices are rare and usually mimick lumbar disc herniations. Back pain and radiculopathy are the main symptoms of lumbar epidural varices. Perineural cysts are radiologically different lesions and should not be confused with epidural varix. A 36-yearold male patient presented to us with right leg pain. The magnetic resonance imaging revealed a cystic lesion at S1 level that was compressing the right root, and was interpreted as a perineural cyst. The patient underwent surgery via right L5 and S1 hemilaminectomy, and the lesion was coagulated and removed. The histopathological diagnosis was epidural varix. The patient was clinically improved and the follow-up magnetic resonance imaging showed the absence of the lesion. Lumbar epidural varix should be kept in mind in the differential diagnosis of the cystic lesions which compress the spinal roots.

Keywords: Epidural; Varix; Perineural cyst; Surgery

\section{Introduction}

Lumbar epidural varices are enlarged venous structures located around the dura mater of the spinal cord. They have been infrequently described in the literature and are rarely accepted as a primary pathophysiological entity [1]. These lesions usually mimick lumbar disc degenerations and herniations [2]. The possible mechanism is the obstruction of the anterior epidural venous flow leading to anterolateral caudal venous distention. Subsequent venous endothelial injury predisposes the patient to varying degrees of thrombosis [3]. Magnetic resonance (MR) imaging characteristics of the epidural varix depend upon the degree of thrombosis within this anomaly. A thrombosed varix is hyperintense on T1-weighted, protondensity, and T2-weighted images, whereas flowing blood is hypointense [4]. The variable hypointensity and hyperintensity on the T2-weighted MR imaging sequences correlates with a partially patent lumen within the varix. The treatment is decompression of partially thrombosed varices by discectomy or coagulation of the varices with bipolar cauter $[1,2,5]$.

We reported a case of lumbar epidural varix presented with radiculopathy and mimicked a perineural cyst. The differential diagnosis of this lesion is discussed with a review of the literature.

\section{Case Report}

A 36-year-old male patient presented to our hospital with right leg pain. He was healthy otherwise. In his neurological examination, mild motor weakness was detected on the plantar flexion of the right foot, as well as absence of the achille reflex on the right side. The MR imaging revealed a hyperintense cystic lesion at the S1 level with compression on the right spinal root and dural sac (Fig.

Received Jan 2, 2012; Revised Jan 20, 2012; Accepted Jan 29, 2012

Corresponding author: Yusuf Izci

Department of Neurosurgery, Gulhane Military Medical Academy, 06018 Etlik-Ankara, Turkey

Tel: +90-312-304-53-18, Fax:+90-312-304-53-00, E-mail: yizci@gata.edu.tr 
1). The radiological diagnosis was perineural cyst. The patient underwent surgery and right L5-S1 hemilaminectomy was performed. A brown-soft mass lesion, which was in connection with the epidural venous plexus, was identified during surgery (Fig. 2A).

This lesion became smaller after coagulation and was removed after cutting the connections with epidural plexus. No massive bleeding occured during the resection of the lesion. The spinal root and dural sac were decompressed. The histological examination of the lesion showed tortuous and dilated vessels that were consistent with the diagnosis of varix (Fig. 2B). The patient was clinically improved after surgery. The postoperative MR imaging at the third month after surgery showed the absence of the varix (Fig. 3).

\section{Discussion}

We report a case of lumbar epidural varix which cause radiculopathy and mimicks perineural cyst in MR examination. The patient was treated surgically and improved clinically in 3 months. Epidural varices in the lumbar spine are acquired lesions that are caused by dilation of the internal vertebral venous plexus $[1,2]$. They are often accompanied by dilation of intervertebral veins and external vertebral venous plexus. The pathophysiological basis of epidural varices is not well known, but there are some speculations [1-3]. A herniated disc material may occlude an epidural vein; subsequently venous dilatation can occur as a result of the valveless nature of the epidural venous plexus [5]. In addition, portocaval hypertension, thrombosis of the inferior vena cava and agenesis of infrarenal segment of inferior vena cava may be responsible for the development of lumbar epidural varix [57]. In our case, we performed MR-venography after the operation, but could not find any obstruction or agenesis in the inferior vena cava. There was no disc herniation in our case, which meant that the occlusion of epidural vein by a herniated disc material was impossible. Based on these observations, it seems that the varix was idiopathic in our case.

The varices in the epidural spaces or in the intervertebral foramina may cause irritation or compression on the thecal sac and spinal roots, which results in radiculopathy [1-3]. Clinical manifestations of epidural varices may be caused by two mechanisms: 1) compression of the thecal sac and the nerve roots by the dilated veins or irritation of the roots by the dilated veins; and 2) high pressure in the epidural veins that is transmitted to the perimedullary veins draining the spinal cord and the nerve roots [5]. In our patient, the varix compressed on the spinal root and caused radiculopathy. The patient improved after decompression of the root. MR imaging is a gold
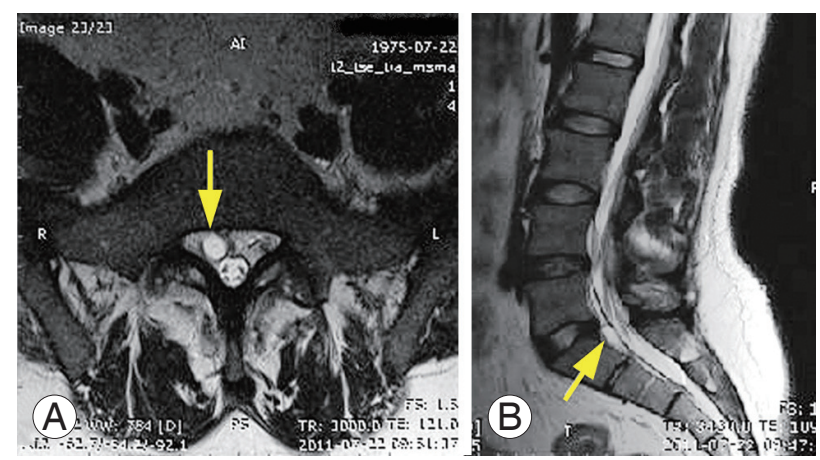

Fig. 1. Preoperative T2-axial (A) and T2-sagittal (B) magnetic resonance imaging show hyperintense cystic lesions compressing the right spinal root. The yellow arrow shows the lesion.
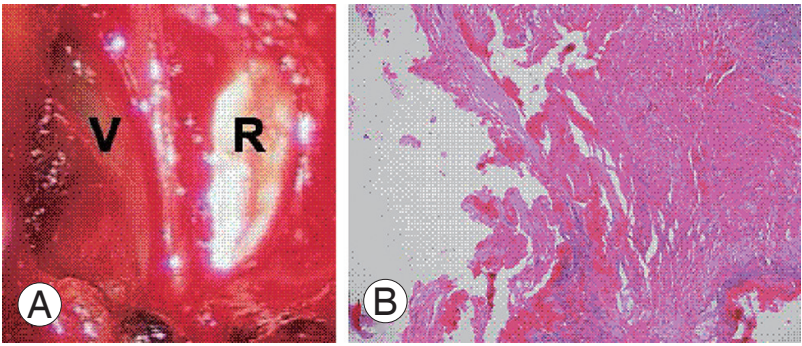

Fig. 2. (A) Intraoperative view of the epidural varix (V), which compressed the spinal root (R) above the sacrum. (B) Large and tortuous vessels were seen in the histological examination $(\mathrm{H} \& \mathrm{E}, \times 100)$.
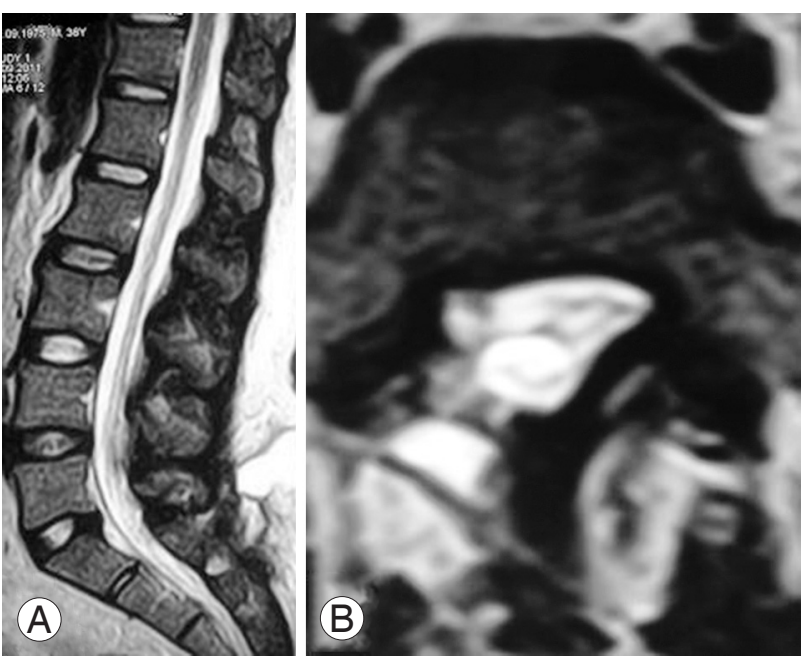

Fig. 3. Postoperative T2-sagittal (A) and T2-axial (B) magnetic resonance slices show the absence of the lesion. 
standard for the diagnosis. The epidural veins could not be visualized on MR studies under normal conditions. Routine MR techniques demonstrated epidural varices, in their maximum manifestation, as zones of a signal void, which repeated the contours of particular veins and the main epidural venous pathways (of anterior and, less often, posterior longitudinal veins, intervertebral veins, and conglomerates of veins). MR imaging seldom shows dilated intervertebral veins causing nerve root compression [5]. In our case, the lesion was hyperintense in T2and hypointense in T1-weighted MR slices. There was no contrast enhancement on the lesion after intravenous gadolinum administration. This was related to very slow venous flow and thrombosis.

The differential diagnoses of lumbar epidural varices include herniated disc, abscess, tumor, hematoma, and synovial cyst $[1,2,5-9]$. The varices are sometimes indistinguishable from a sequestered disc fragment [2]. Perineural cysts have not previously been reported in the differential diagnosis of epidural varices. In our case, the MR imaging findings, however, are more consistent with perineural cysts than a thrombus and/or slow blood flow within the epidural varix. Hanley et al. [3] divided the epidural varices into 3 types. Type 1 is thrombosed dilated epidural vein, type 2 is epidural vein dilation due to activity and type 3 is submembraneous epidurallycontained hematoma. Our case was type 1 according to Hanley's classification.

Surgery is the main treatment of lumbar epidural varices. However, Tofuku et al. [10] reported a case of lumbar epidural varix at L3 level which was spontaneously regressed within 2 weeks. They did not perform surgical treatment. The choice of surgical method depends on the type of varix and clinical manifestations [5]. The aims of the surgical intervention are the decompression of the thecal sac and nerve roots, and elimination of the irritation. Complete interruption of the blood flow in the epidural veins should be avoided during surgery because these veins are the only channels of collateral blood flow [5]. In our case, we did not remove all of the epidural veins, but we disconnected the varix from the venous plexus and then removed it successfully after coagulation.

To conclude, lumbar epidural varix is a specific lesion of the spinal canal. The diagnosis is difficult, but the treatment is unique. Perineural cysts should be kept in mind in the differential diagnosis. A precise diagnostic workup and well-planned surgery will lead to a successful outcome.

\section{Conflict of Interest}

No potential conflict of interest relevant to this article was reported.

\section{References}

1. Zimmerman GA, Weingarten K, Lavyne MH. Symptomatic lumbar epidural varices: report of two cases. J Neurosurg 1994;80:914-8.

2. Aoyama T, Hida K, Akino M, Yano S, Saito H, Iwasaki Y. Radiculopathy caused by lumbar epidural venous varix: case report. Neurol Med Chir (Tokyo) 2008;48:367-71.

3. Hanley EN Jr, Howard BH, Brigham CD, Chapman TM, Guilford WB, Coumas JM. Lumbar epidural varix as a cause of radiculopathy. Spine (Phila $\mathrm{Pa}$ 1976) 1994;19:2122-6.

4. Paksoy Y, Gormus N. Epidural venous plexus enlargements presenting with radiculopathy and back pain in patients with inferior vena cava obstruction or occlusion. Spine (Phila Pa 1976) 2004;29:2419-24.

5. Slin'ko EI, Al-Qashqish II. Surgical treatment of lumbar epidural varices. J Neurosurg Spine 2006;5:41423.

6. Siam L, Rohde V. Varicosis of the venous epidural plexus caused by portocaval hypertension mimicking symptomatic lumbar disc herniation: case report and review of the literature. Cent Eur Neurosurg 2011;72:155-8.

7. Dudeck O, Zeile M, Poellinger A, Kluhs L, Ludwig WD, Hamm B. Epidural venous enlargements presenting with intractable lower back pain and sciatica in a patient with absence of the infrarenal inferior vena cava and bilateral deep venous thrombosis. Spine (Phila Pa 1976) 2007;32:E688-91.

8. Genevay S, Palazzo E, Huten D, Fossati P, Meyer O. Lumboradiculopathy due to epidural varices: two case reports and a review of the literature. Joint Bone Spine 2002;69:214-7.

9. Wong CH, Thng PL, Thoo FL, Low CO. Symptomatic spinal epidural varices presenting with nerve impingement: report of two cases and review of the literature. Spine (Phila Pa 1976) 2003;28:E347-50.

10. Tofuku K, Koga H, Yone K, Komiya S. Spontaneous regression of symptomatic lumbar epidural varix: a case report. Spine (Phila Pa 1976) 2007;32:E147-9. 